\title{
Severe hypocalcaemia in a COVID-19 female patient
}

\author{
Edmond Puca1', Entela Puca2 ${ }^{2}$ Pellumb Pipero', Holta Kraja ${ }^{3}$ and Najada Como ${ }^{1}$ \\ 1Service of Infection Diseases, University Hospital Center, Tirane, Albania, 2Service of Endocrinology, Amerikan \\ Hospital, Tirane, Albania, and 3 Service of Anaesthesia and Reanimation, University Hospital Center, Tirane, Albania
}

Correspondence should be addressed to E Puca

Email

entelalamcaj@yahoo.com

\section{Summary}

Comorbidities are a risk factor for patients with COVID-19 and the mechanisms of disease remain unclear. The aim of this paper is to present a case report of an COVID-19 patient with severe hypocalcaemia. This is a report of an 81-year-old female, suffered from myalgia and fatigue for more than 3-4 weeks. Fever and cough appear 2 days before she presented to the emergency room. On physical examination, she was febrile with a temperature of $38.8^{\circ} \mathrm{C}$, accompanied by cough, sore throat, headache, fatigue, and muscle ache. Her past medical history was remarkable with no chronic disease. She had lymphopenia. Laboratory test revealed moderate liver dysfunction, hypoalbuminemia, and severe hypocalcaemia (serum corrected calcium level: $5.7 \mathrm{mg} / \mathrm{dL}$ ). Parathyroid hormone (PTH) was $107.9 \mathrm{pg} / \mathrm{mL}$ (range: 15-65) and 25(OH)2D levels was $4.5 \mathrm{ng} / \mathrm{mL}$ (range: $25-80$ ). Chest CT scan detected peripheral ground-glass opacity. Throat swab for coronavirus by RT-PCR assay tested positive for the virus. She was treated with lopinavir/ritonavir, third generation cephalosporin, anticoagulant, daily high-dose calcium acetate, vitamin $D_{3}$, fresh frozen plasma and oxygen therapy. She was discharged after two negative throat swab tests for coronavirus by conventional RT-PCR.

\section{Learning points:}

- Comorbidities are a risk factor for patients with COVID-19.

- Laboratory findings are unspecific in COVID-19 patients; laboratory abnormalities include lymphopenia, elevated of $\mathrm{LDH}, \mathrm{CPK}$ and the inflammatory markers, such as $\mathrm{C}$ reactive protein, ferritinemia and the erythrocyte sedimentation rate.

- In addition to inflammatory markers, in COVID-19 patients it is crucial to check the level of vitamin D and calcium.

- There may be a correlation between vitamin D deficiency and the severity of COVID-19 disease.

\section{Background}

COVID-19 is a new disease with serious consequences for public health. The pathogenic mechanisms of the disease and organ dysfunctions remain to be unclear. Maybe a lot of factors such as hypertension, diabetes, autoimmunity, gender, predisposition or other diseases interrupts with its mechanisms $(1,2)$. One of them may be hypocalcaemia, which is common in critically ill patients. Many factors influence serum calcium concentration such as parathyroid hormone (PTH), vitamin D level, calcitonin, hypoalbuminemia, and electrolyte disturbances $(3,4,5)$.
In this report, we present a case of an 81-year-old female confirmed with COVID-19 infection who developed asymptomatic hypocalcaemia with severe hypocalcaemia and vitamin D deficiency.

\section{Case presentation}

An 81-year-old female presented to the emergency room, complaining of fatigue, myalgia, and fever for the previous 2 days and shortness of breath. Despite preserved appetite, 
her nutritional status was poor for the previous $2-3$ weeks. She was house-bound. Three to 4 weeks before coming in to the hospital she started to complain of fatigue and myalgia. The last 2 days she experienced extreme fatigue, fever and cough and loss of taste and smell. The patient was not well oriented. Her physical examination revealed blood pressure 110/65 $\mathrm{mmHg}$, heart rate 45-52/b.p.m. with rare extrasistoles, respiratory rate $24-28$ breaths/ min and finger oxygen saturation was $92-93 \%$ in air room. Her muscle weakness was self-evident and she could hardly get to her feet without help. Complete blood count $(\mathrm{CBC})$ showed haemoglobin of $13.0 \mathrm{mg} /$ $\mathrm{dL}$, white blood cell count of $5400 / \mu \mathrm{L}$, lymphocyte were $700 / \mu \mathrm{L}$ and platelet count of $237000 / \mu \mathrm{L}$. Her metabolic panel revealed severe hypocalcaemia $4.8 \mathrm{mg} / \mathrm{dL}$, serum corrected calcium level was calculated as $5.7 \mathrm{mg} / \mathrm{dL}$, aspartate aminotransferase (AST) $112 \mathrm{U} / \mathrm{L}$ (range: 0-35), alanine aminotransferase (ALT) $77 \mathrm{U} / \mathrm{L}$ (range: 0-45), total bilirubin $0.9 \mathrm{mg} / \mathrm{dL}$ (range: $0.3-1.2$ ), blood urea nitrogen $85 \mathrm{mg} / \mathrm{dL}$ (range: 10-43), serum creatinine $0.7 \mathrm{mg} / \mathrm{dL}$ (range: 0.6-1.2), lactate dehydrogenase (LDH) $864 \mathrm{U} / \mathrm{L}$ (range: 125-250), creatine phosphokinase (CPK) $1087 \mathrm{U} / \mathrm{L}$ (range: 0-171), total protein $6.0 \mathrm{~g} / \mathrm{dL}$ (range: $6.2-8.3$ ) and hypoalbuminemia $2.9 \mathrm{~g} / \mathrm{dL}$ (range: $3.5-5.2$ ) and normal magnesium level $2.1 \mathrm{mg} / \mathrm{dL}$ (range: $1.8-2.4 \mathrm{mg} / \mathrm{dL}$ ). Based on her complaints, physical examination and laboratory tests, COVID-19 infection was suspected. Activated prothrombin partial time (APTT) was 32.9 s (range: 20-35), INR 1.31 (range: 0.8-1.2), fibrinogen $393 \mathrm{mg} / \mathrm{dL}$ (range: 169-515) and ferritinemia was $850 \mathrm{ng} / \mathrm{mL}$ (range: 5-204). Blood gas analyses were: $\mathrm{pH} 7.441 ; \mathrm{pCO}_{2}$ was 32.3 $\mathrm{mmHg} ; \mathrm{PO}_{2}$ was $53.7 \mathrm{mmHg}$ (range: $83-108$ ); $\mathrm{Ca}++2.01$ $\mathrm{mg} / \mathrm{dL}$ (range: 4.49-5.32) and lactate $2.1 \mathrm{mmol} / \mathrm{L}$ (range: 0.4-2.20). The results of other examinations revealed: procalcitonine $0.06 \mathrm{ng} / \mathrm{mL}$, C reactive protein was 2.14 $\mathrm{mg} / \mathrm{dL}$ (range: $0-0.5$ ), parathyroid hormone (PTH) was $107.9 \mathrm{pg} / \mathrm{mL}$ (range: $15-65$ ) and $25(\mathrm{OH})_{2} \mathrm{D}$ level was 4.5 $\mathrm{ng} / \mathrm{mL}$ (range: $25-80$ ). Urinary calcium excretion ratio was low $0.53 \%$ (range: $1-2 \%$ ). Blood phosphorus was not evaluated (Fig. 1).

Chest CT scan showed multiple peripheral and central ground-glass opacity that is a strong suggestion for COVID19 infection. Hence, nasopharyngeal swab from the patient was obtained for coronavirus conventional RT-PCR assay that was positive for the virus. She was admitted and treated with ceftriaxone, levofloxacine, lopinavir/ritonavir (200/50 mg) $1000 \mathrm{mg} /$ day, daily high-dose calcium acetate (9000 mg) and vitamin $\mathrm{D}_{3} 200000$ unite, dalteparine sodium $10000 \mathrm{UI} /$ day, oxygen, fresh frozen plasma, human serum albumin and supplementation therapy.
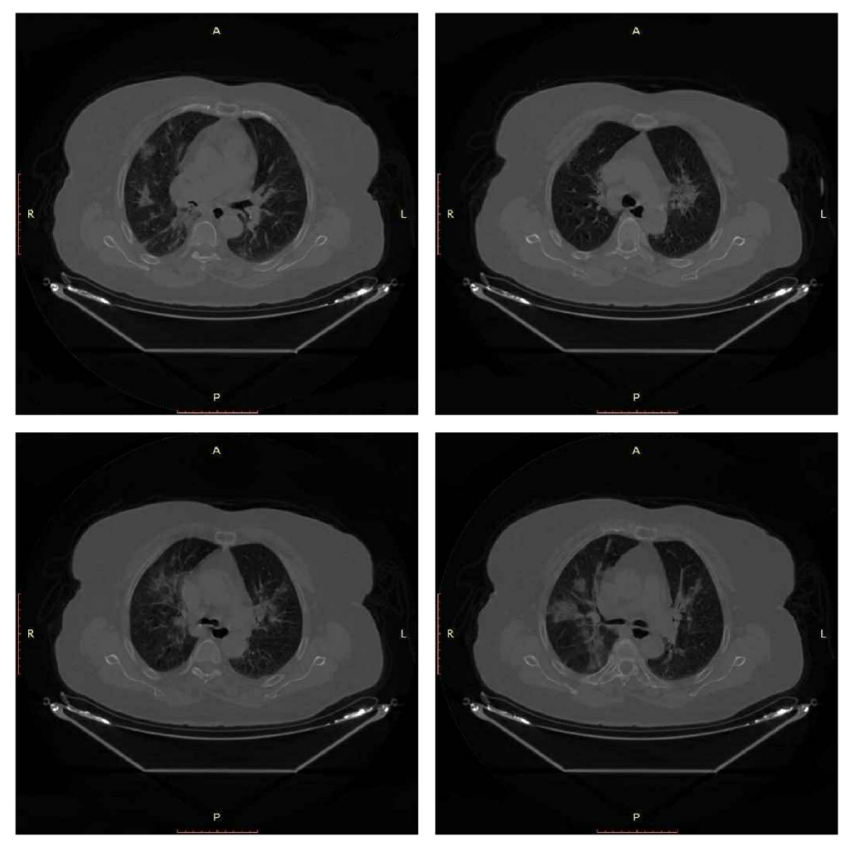

Figure 1

Chest CT scan showed multiple peripheral and central ground-glass opacity.

Then the patient was passed on for meropenem treatment plus supportive care. An additional complication was that the patient had acute respiratory distress syndrome (ARDS), and was treated with non-invasive ventilation oxygen with high flow nasal cannula combined with continuous airway positive pressure (CPAP) plus methylprednisolone in high doses. In spite of a daily dose of calcium of 7000-9000 mg per day, normal calcium was only achieved on the 7th day of admission. On the 15th day after admission the patient had a negative result on throat swab by RT-PCR assay for coronavirus. After that, the patient was discharged from our hospital and transferred to another service to support her in pulmonary physiotherapy.

\section{Investigation}

Chest CT scan showed multiple peripheral and central ground-glass opacity, which is a strong indication of COVID-19 infection. Nasopharyngeal swab sample was obtained from the patient to test for coronavirus by conventional RT-PCR assay and it was positive for the virus. Other laboratory examinations were carried out.

\section{Treatment}

Daily high-dose calcium acetate $(9000 \mathrm{mg}$ ) and vitamin $\mathrm{D}_{3} 200000$ units, dalteparine sodium $10000 \mathrm{UI} /$ day, 
oxygen, fresh frozen plasma, human serum albumin and supplementation therapy were given.

The patient was then put on meropenem treatment plus supportive care. Complications with acute respiratory distress syndrome (ARDS) was treated with non-invasive ventilation oxygen with high flow nasal cannula combined with continuous airway positive pressure (CPAP) plus methylprednisolone in high doses.

\section{Outcome and follow-up}

After treatment, the patient was discharged from our hospital and transferred to another service to support her in pulmonary physiotherapy.

\section{Discussion}

In this report, we present the case of a COVID-19 female patient associated with asymptomatic severe hypocalcaemia due to severe vitamin $\mathrm{D}$ deficiency. COVID-19 patients typically in their disease course present with fever, cough, dyspnea, and myalgia, and sometimes the disease can be complicated with severe pneumonia (1). Laboratory findings are unspecific in COVID-19 patients; however, the predominant laboratory abnormalities include lymphopenia, elevated of LDH, CPK and the inflammatory markers, such as $\mathrm{C}$ reactive protein, ferritinemia and the erythrocyte sedimentation rate. The lungs are the main organ involved in this disease. Severe pneumonia caused by Cov-SAR-2 virus is often associated with cytokine storm, uncontrolled inflammatory cytokines contributing to acute lung injury and $\operatorname{ARDS}(1,6)$. Our patient had complications including ARDS and was treated with methylprednisone plus non-invasive ventilation oxygen high flow nasal cannula combined with CPAP. Chest CT scan is an important part of disease detection for patients suspected of having COVID-19 infection (Fig. 1). CT findings were multifocal, uni- or bi-lateral, peripheral, and basal-predominant ground-glass opacities (1). Based on her clinical course, laboratory findings and staying at home, we concluded that her severe hypocalcaemia was mainly related to COVID-19 infection and especially caused by endotoxemia. The deficiency of vitamin D in Albania is a common finding (7). The aetiology of hypocalcaemia in critical illness is multifactorial starting with food, non-exposure to sunlight and severe infectious diseases. Severe patients are at risk of hypocalcaemia due to the effect of inflammatory mediators such was in this case. Duval et al. state that severe hypocalcaemia, defined by a serum calcium level $<1.9 \mathrm{mmol} / \mathrm{L}$ or $<7.6 \mathrm{mg} / \mathrm{dL}$, is often considered an emergency because of cardiac arrhythmias or seizure (3). Our patient had bradycardia and extrasystoles and the serum corrected calcium level was $5.7 \mathrm{mg} / \mathrm{dL}$. Hypocalcemia is treated with calcium and vitamin D analogues (8). In this case, the patient had hypoprotinemia and hypoalbuminemia that was corrected with fresh frozen plasma and albumin. In addition, we concluded that vitamin D deficiency was mainly related to COVID-19 infection. So the patient due to old age had stayed indoors for more than four months. Jia-Kui Sun et al. report that hypocalcaemia may be associated with an imbalance of vitamin D and PTH in the acute phase of COVID-19 and that mortality can be raised by a very low level of hypocalcaemia (9). Other markers such as CRP, ALT, TNI, D-dimer, ferritinemia and lymphocytopenia are increased in critical COVID-19 patients and maybe all of these markers alone or together with others can contribute to increase in fatality. Rhodes et al. suggest that there may be a correlation between vitamin D level and COVID-19 linked directly or indirectly with other diseases such as hypertension, diabetes, obesity to the severity of COVID-19 disease (10). However the patient, after 15 days in hospital tested negative for coronavirus in two swab samples of the throat by RT-PCR assay. After that, the patient was discharged from our hospital and transferred to another service to support her in pulmonary physiotherapy.

\section{Declaration of interest}

The authors declare that there is no conflict of interest that could be perceived as prejudicing the impartiality of the research reported.

\section{Funding}

This work did not receive any specific grant from any funding agency in the public, commercial or not-for-profit sector.

\section{Patient consent}

Patient consent has been received.

Author contribution statement

All authors have been part of treatment team.

\section{References}

1 Chen T, Dai Z, Mo P, Li X, Ma Z, Song S, Chen X, Luo M, Liang K, Gao S, et al. Clinical characteristics and outcomes of older patients with coronavirus disease 2019 (COVID-19) in Wuhan, China (2019): 
a single-centered, retrospective study. Journals of Gerontology: Series A Biological Sciences and Medical Sciences 202075 1788-1795. (https:// doi.org/10.1093/gerona/glaa089)

2 Elgendy IY \& Omokehinde TR. A rare cause of hypocalcemia. American Journal of Case Reports 201314 113-115. (https://doi. org/10.12659/AJCR.883889)

3 Duval M, Bach-Ngohou K, Masson D, Guimard C, Le Conte P \& Trewick D. Is severe hypocalcemia immediately life threatening? Endocrine Connections 20187 1067-1074. (https://doi.org/10.1530/ EC-18-0267)

4 Fong J \& Khan A. Hypocalcemia: Updates in diagnosis and management for primary care. Canadian Family Physician 201258 158-162.

5 Sun JK, Zhang WH, Zou L, Liu Y, Li JJ, Kan XH, Dai L, Shi QK, Yuan ST \& Yu WK. Serum calcium as a biomarker of clinical severity and prognosis in patients with coronavirus disease 2019: a retrospective cross-sectional study. Critical Care and Emergency Medicine 202012 11287-11295. (https://doi.org/10.18632/ aging.103526)
6 Rubino S, Kelvin N, Bermejo-Martin JF \& Kelvin D. As COVID-19 cases, deaths and fatality rates surge in Italy, underlying causes require investigation. Journal of Infection in Developing Countries 2020 14 265-267. (https://doi.org/10.3855/jidc.12734)

7 Puca E, Bitri S, Ylli A \& Puca E. Assessment of Vitamin D 3 Status in General Population. BioScientifica, 2012. (available at: https://www endocrine-abstracts.org/ea/0029/ea0029p262)

8 Cabrer M, Serra G, Gogorza MS \& Pereg V. Hypocalcemia due to 22q11.2 deletion syndrome diagnosed in adulthood. Endocrinology, Diabetes and Metabolism Case Reports 20182018 170140. (https://doi. org/10.1530/EDM-17-0140)

9 Sun J-K, Sun F, Wang X, Yuan S-T, Zheng S-Y \& Mu X-W. Risk factors and prognosis of hypoalbuminemia in surgical septic patients. PeerJ 20153 e1267. (https://doi.org/10.7717/peerj.1267)

10 Rhodes JM, Subramanian S, Laird E \& Kenny RA. Editorial: low population mortality from COVID-19 in countries south of latitude 35 degrees north supports vitamin $\mathrm{D}$ as a factor determining severity. Alimentary Pharmacology and Therapeutics 202051 1434-1437. (https://doi.org/10.1111/apt.15777)

Received in final form 7 September 2020

Accepted 26 November 2020 